\title{
MICROCOMPUTERS IN FLUID POWER- PROBLEM SOLVERS OR PROBLEM GENERATORS?
}

\author{
J. Watton \\ Dept. of Mechanical Engineering and Energy Studies \\ University College Cardiff \\ Cardiff, U.K.
}

\section{ABSTRACT}

This paper attempts to bring together a number of issues relating to the use of microcomputers in three distinct areas: $C A D$, real-time control and condition moritoring. Scme comments and suggestions that might be of value when considering future developments are included.

KEYWORDS

Fluid Power, Microcomputers.

\section{INTRODUCTION}

The application of microprocessors, via a microcomputer system, represents an exciting development in electrohydraulic systems design, and would appear to have an unbounded range of applications. However, it is still important to ask first whether or not the addition of a microcomputer is justified on a reliability/repeatability basis and/or on a cost basis, etc. There are many existing industrial systems, such as forging presses, that utilise microprocessor technology in a variety of forms. Modification to incorporate new techniques of digital electrohydraulic control may therefore be cost effective in such systems. This may not be so in smaller high-precision systems where the introduction of microprocessor technology has more of a novelty value than a commercial value.

The ingenuity of the fluid power system designer will always produce novel solutions to industrial problems. When deciding to implement such solutions the following broad issues may be worth considering:-

1) Can the system design process be improved?
2) Can the component complexity be simplified?

3) Will the introduction of new components together with the relevant microprocessor reduce costs?

4) Will the control strategy be improved or could it be adapted to changing operating conditions?

5) Will component and/or system reliability be improved?

6) Will the system be better maintainable due to the use of low-cost components or the ability to detect failure/ deterioration using digital logic?

Many of these points hide a host of other issues that need to be addressed in relation to the specific application of the microcomputer. Consider then some typical areas of application:-

THE CAD ENVIRONMENT

Digital computer simulation of electrohydraulic control systems and components is now widely used and accepted as a desirable, and sometimes essential, element of the design stage of a major hydraulic project. Digital simulation in the context of this section refers to time domain solutions to the system non-linear equations, as opposed to the use of digital computers for standard analyses such as Nyquist plots, frequency response, etc. of linear systems. There are perhaps three possible strategies that may be adopted by the design Engineer with access to a computer system when considering its application to numerical analysis. The possibilities are:-

i) Treat the system equations merely as a set of mathematical equations that could be treated just like any other set of dynamical equations. A solution technique using any of the established numerical methods [for 
example 1-4] may then be developed. This has the disadvantage that the program written may be of limited use with respect to other systems simulations that may appear, but it does have the advantage of time and financial savings when compared to an all-embracing simulation philosophy.

ii) A standard simulation package, that can be applied to any set of control system equations, may be purchased and modified slightly to accommodate the notation of hydraulic systems. There are a variety of such packages in use [5-8], many of which may be directly applied to hydraulic systems simulation. The major disadvantages of this approach is that the user will probably have a limited knowledge of the program. There is therefore often minimum flexibility to modify parts of the program, such as the integration technique, should problems of simulation arise. However, many modern packages are relatively low-cost and can usually be implemented after only a few hours of hands-on experience.

iii) A generalised hydraulic simulation package may be purchased to cover typical components and systems met in practice. This perhaps may be considered the ultimate goal of the system designer, although it is clear that packages that do exist [9-13] have required many man-years of effort in their development.

Many of the approaches discussed have been adopted and a considerable success has been achieved using a wide variety of numerical methods. A generalised simulation package is then initiated by setting up what is termed a system MACRO with block descriptions representative of the circuit components.

Such a MACRO could be as follows:-

\begin{tabular}{|c|c|c|c|c|}
\hline block & block & block & description & inputs \\
\hline type & $\overline{\text { output }}$ & no. & & \\
\hline pump & $Q_{1}$ & $\overline{1,}$ & PV1, & 3,7 \\
\hline & $Q_{2}$ & 2, & PV2, & 3,7 \\
\hline line & $\mathrm{P}_{1}$ & 3, & LN1, & $1,4,9$ \\
\hline motor & $Q$ & 4, & MFA, & $6,3,7$ \\
\hline & & $\begin{array}{r}5, \\
\text { etc }\end{array}$ & $M F B$, & $6,3,7$ \\
\hline
\end{tabular}

The setting up procedure is of course merely a simple means of linking the appropriate hydraulic components that are already stored in the package in the form of suitable algebraic or differential equations. These individual blocks may contain many sub-blocks that are needed to solve the relevant equations. They are often referred to as the system MICROs and will be automatically set up and sub-block numbered after execution of the system MACRO.

The main criticism of this approach to $\mathrm{CAD}$ is that it requires some further circuit modification to achieve the correct form for the package. The conventional hydraulic circuit diagram is then not used and the hydraulic "feel" has in a sense been diverted.

A new-generation CAD approach is being developed by the writer and his research group, and is based upon the use of screen graphics that look like the actual hydraulic circuit. This is being supported by XANALOG software [14], which may be directly implemented using a mousemenu approach. Sub models are then dragged onto the screen using the mouse and then interconnected to form whatever circuit is required. These sub models may be algebraic functions, algorithms, or actual circuit components such as motors, servovalves etc, and may themselves contain further sub models. Some examples of typical sub models are shown in Fig.1.
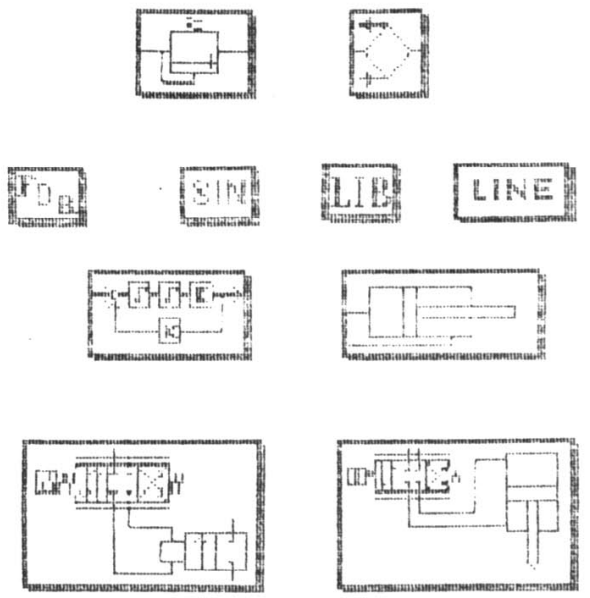

Fig.1 Screen dumps of some typical component sub models

A typical application being considered at present is high speed digital control of forging presses, and part of a typical simulation is shown in Fig.2.

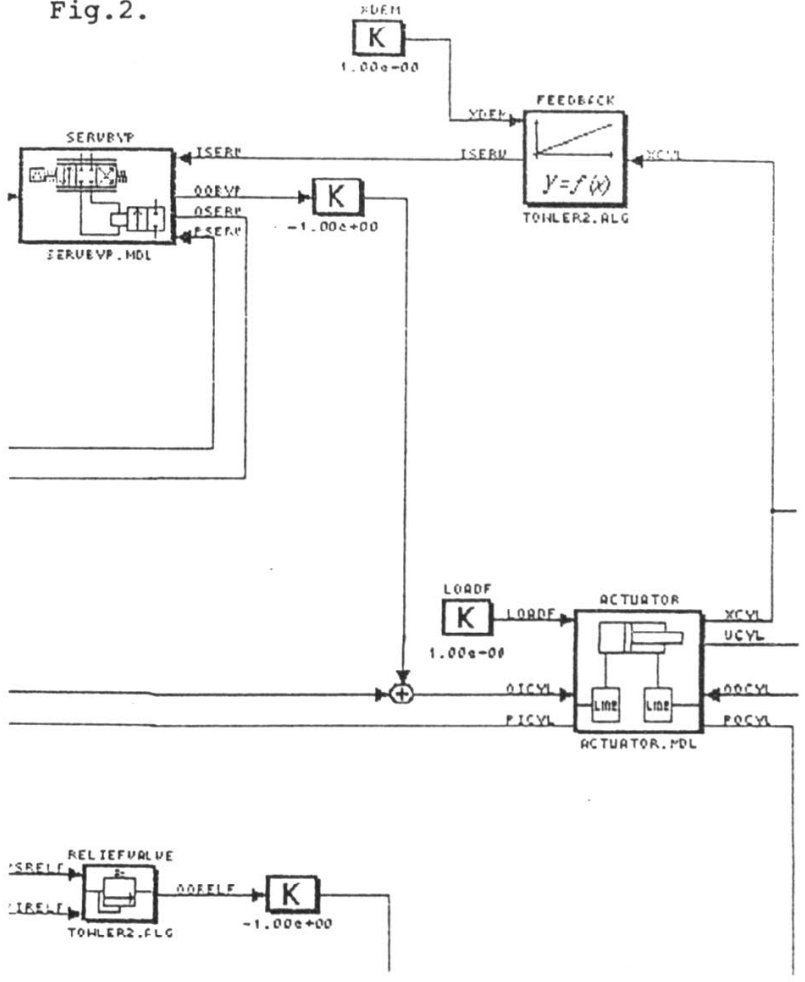

Fig.2 Part of a hydraulic system simulation as seen on the computer graphics display 
The actuator sub model, for example, contains 33 further sub models built up from the system library.

This approach is therefore extremely versatile and may be made more powerful by the addition of fast processors enabling real-time control to be implemented. It does have one drawback at present in that two lines are usually required to interconnect components and representing pressure and flow at that point in the circuit. In reality the components would be connected by one line, or two lines for a servovalve which requires four lines in the CAD package. The next generation will then have to correct this temporary restriction.

REAL TIME DIGITAL CONTROL

There are a number of application areas that exist and are being developed, such as:-

i) test rig performance evaluation with test sequence control,

ii) sequential control of industrial systems

iii) component control

iv) "conventional" feedback control algorithm implementation incorporating system identification.

Items i) and ii) might be considered as upgrading of existing automated test and manufacturing methods, the microcomputer system however giving far more flexibility at a reduced cost and with a far greater reliability. The development of components with integral microprocessor control presents a fascinating challenge to the designer. It has no doubt been the desire of servovalve manufacturers for many years to produce a low-cost digitally driven valve with a comparable dynamic performance. Some interesting approaches have been established $[15,16,17,18]$, many using the pulse-width-modulation technique of electrical switching. The use of proportional solenoids is now common, and the continual improvement of such elements may make them a commonplace interface between microprocessor and valve spools.

A new development in fast acting solenoid valves is shown in Fig.3.

This solenoid valve is capable of switching hydraulic powers of up to $15 \mathrm{~kW}$ with energisation and de-energisation times typically of $12 \mathrm{~ms}$. These times are achieved by combining CAD techniques of electromagnetic circuit design and electronic switching techniques. Typical responses are shown in Fig. 4.

Research needs to be carried out to improve the response times even more and of course to keep costs down to the user.

It is perhaps relevant at this stage to ask what role superconducting materials may have in the future. Critical temperatures are increasing [19] and it may be practical in the near future to apply superconducting solenoids to larger spindle flow valves controlling high powers for use in heavy industry.

Perhaps the time is not too far away when a common "valve block" with appropriate position, pressure or flow transducer may serve a variety of

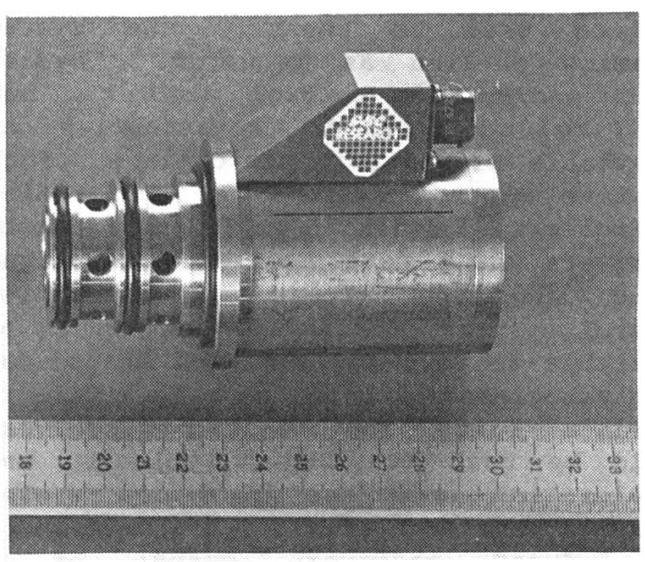

Fig.3 A fast acting valve courtesy of GEC Engineering Research Centre, Cambridge Road, Whetstone, Leicester, UK.

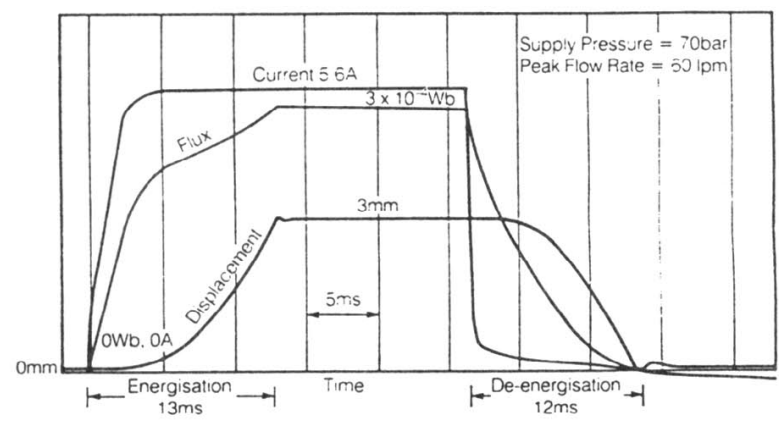

Fig.4 Fast acting solenoid valve response courtesy of GEC Engineering Research Centre, Cambridge Road, Whetstone, Leicester, UK.

applications, each currently requiring a separate component. In a similar manner it may be possible to "program" a low-cost microprocessor controller for a variable displacement pump to give constant flow, pressure or power output.

However, such applications are only as good as the transducers used, and further consideration must be given to instrumentation performance criteria such as linearity and sensitivity as well as cost. Inevitably it therefore seems that microprocessor development is inherently linked to appropriate sensor development and integration with typical electrohydraulic components.

From a traditional feedback control system point of view, there are many possibilities for the use of microprocessor control. Many electrohydraulic systems will have variable loads, pressure supply changes, variable speed conditions, etc, which will change the dynamic characteristics of a system element. The flow and pressure coefficients of a servovalve immediately come to mind here, since they are influenced by such changes 
previously mentioned. The microprocessor system is now of immense value since it may be used to identify the system dynamics on-line as required. System gains and/or the control algorithm may then be modified to re-establish an acceptable closed-loop performance. Such adaptive control systems or self tuning controllers could implement state observers or a more heuristic technique using adaptive filters. In position control systems, for example, it would be desirable to have the position transducer with associated electronics only. This is possible since reduced-state observers could be used to predict velocity and acceleration once the open-loop system dynamics have been identified [20-26]. Reduced observer control of a closed-loop motor position control system is shown in Fig.5, using an algorithm based upon a direct z-transformation of the linear system equations.

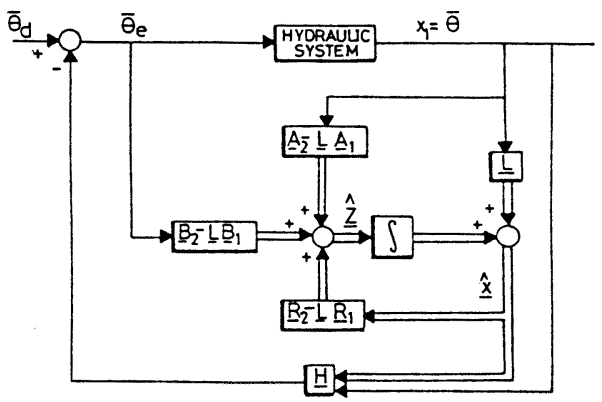

a) Control system

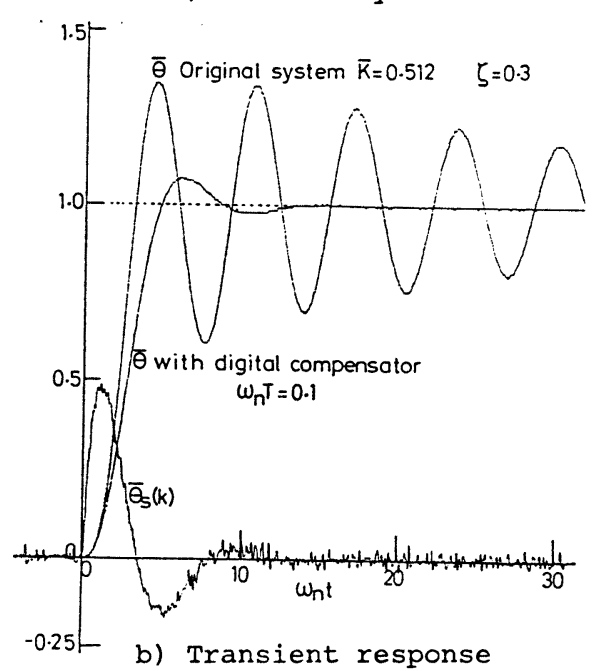

Fig.5 Reduced observer control of a motor

In this control scheme the observer determines the appropriate motor velocity and acceleration states and then uses an optimum feedback law to produce the desired response. This approach in some ways may be preferable to the more usual self-tuning approach using $F\left(z^{-1}\right)$ and $\mathrm{H}\left(\mathrm{z}^{-1}\right)$ filters.

However, it might be timely to ask whether more effort should be put into power and efficiency control. This is often regarded as important in indistry, particularly in high power systems with loads continuously changing. Consider, for example, a servovalve controlled motor system with feedback. In this application considered by the writer, thought is being given to the use of proportional relief valves for continuously changing servovalve supply pressure to maintain optimum performance. Fig.6a shows the control system and Fig.6b shows measured power transferred to the motor at constant speeds.

Steady-state non-linear theory proved remarkably accurate in predicting the pressure differential at a fixed gain and speed at which maximum power is transferred, and this is used in the control algorithm. Problems are associated with this control scheme since linearised theory suggests that proportional pressure feedback produces instability. It is possible to introduce phase advance, but non-linear simulation shows that a large amount of phase lead is needed, effectively cancelling the poles of the proportional relief valve dynamics. The response is improved but could become quite oscillatory. More effort is therefore needed in this area. Fig.7 shows a typical transient performance.

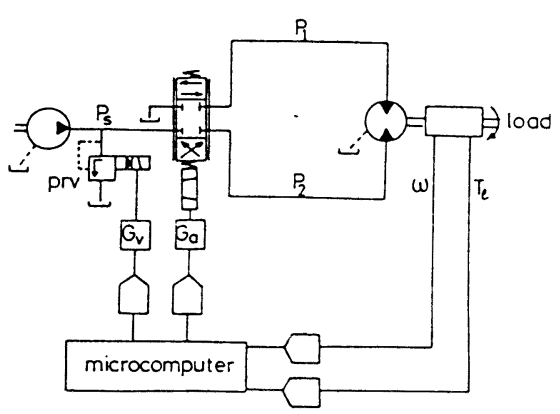

a) Control system

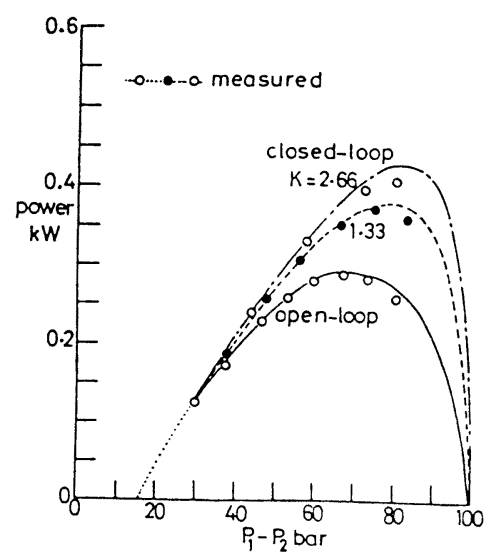

b) Power transfer characteristic

Fig.6 Speed control system with optimum power control 


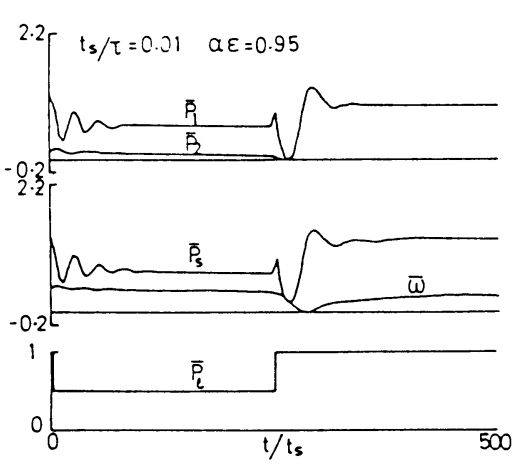

Fig.7 Optimum power transfer control for a closed-loop motor speed control system

Power may be minimised, together with position error being driven to zero, in position control systems using single-rod actuators, by the use of a symmetricallyunderlapped spool in the servovalve [27]. It has been shown by the writer that such systems without an underlapped spool will always give a position error. This may be driven to zero in the modified system by observing a simple relationship between load force and supply pressure. Again this suggests the use of a proportional relief valve to constantly change the supply pressure from load force measurement. An interesting feature of the linearised analysis of this system is that closed-loop stability is independent of the relief valve dynamics, although the position response to changes in load force is dependent upon such dynamics. The proportional relief valve may be controlled by a signal proportional to the load force, and system gains may again be varied by the microcomputer to give optimum response. Fig.8a shows the control scheme and Fig.8b shows a typical response to changes in load force at a fixed demanded position.

Also shown in Fig.8 is the position response, and hence error, that occurs with a constant supply pressure system. Note also that supply power is minimised when not required by the load. Care must be taken however in restricting the variation in supply pressure to sensible limits.

All the literature, to the writer's knowledge, uses small step inputs to identify and adapt the closed-loop performance. This is often unacceptable in practice from a test signal point of view particularly with high power systems. The normal operation of the plant may also not produce idealised step inputs and it is well known that under these conditions the identification algorithms may give incorrect parameter predictions. Also the low frequency of the input test signals required could be unacceptable in practice. A further problem in cylinder position control systems using servovalves with spool underlap is that the system gain is directional-dependent and also different at null. An indication of this is given in Fig. 9.
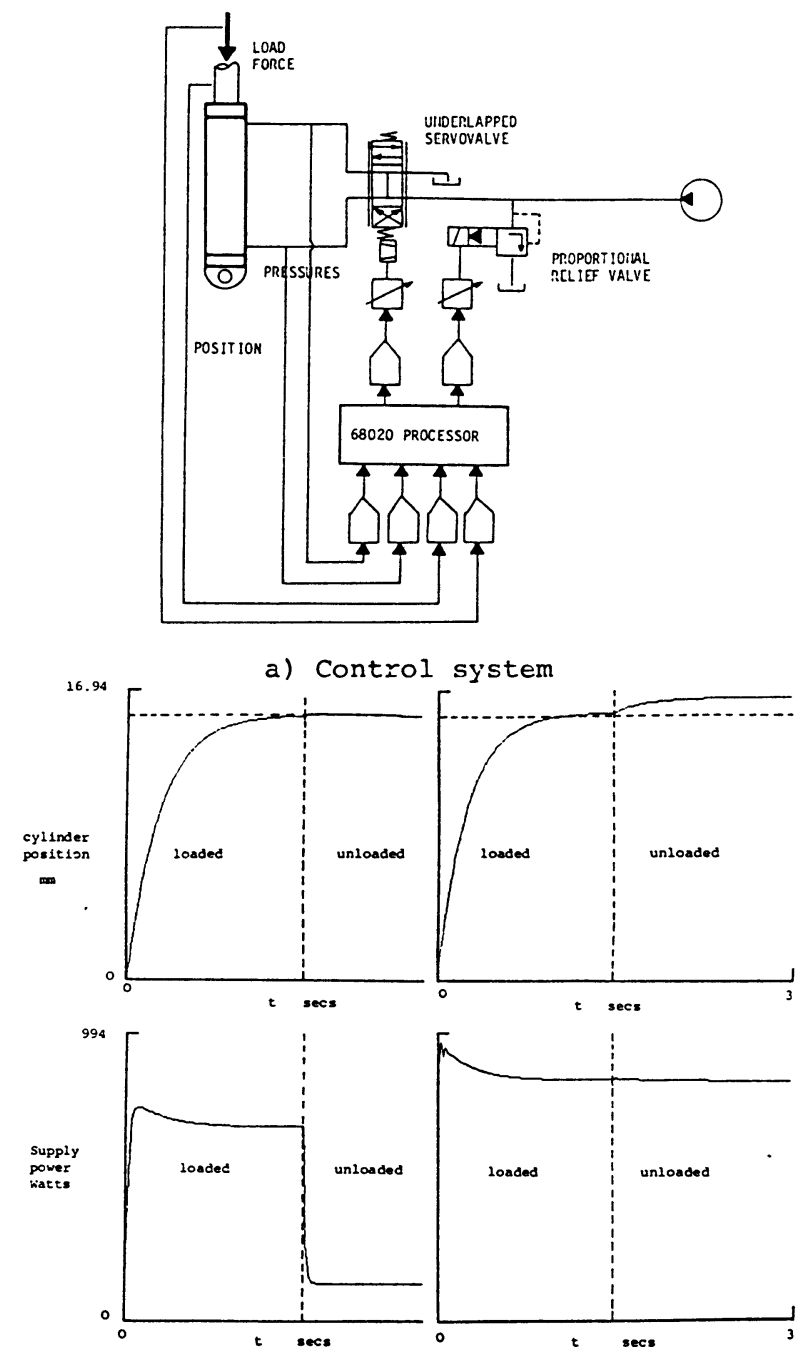

b) Typical closed-loop response

Fig.8 Position control of a single-rod cylinder with supply pressure control

The correct choice of system gain is essential in any adaptive control system and a gain slightly below the null value is usually selected. It is therefore essential that input test signals identify the maximum system gain. An alternative approach not yet apparently used would be to use a pseudo random binary test signal (prbs) and identify the open-loop transfer function completely using fast Fourier Transform methods as indicated in Fig. 10. It would only be necessary to use a simple feedback algorithm based upon a desired closed-loop performance. Note from Fig. 10 that it is proposed that identification and correction be done external to an analogue closed-loop which may be designed to accommodate the poorest dynamic operating conditions.

\section{CONDITION MONITORING}

The microcomputer in systems monitoring may take on a more advanced nature than merely checking pressures, 


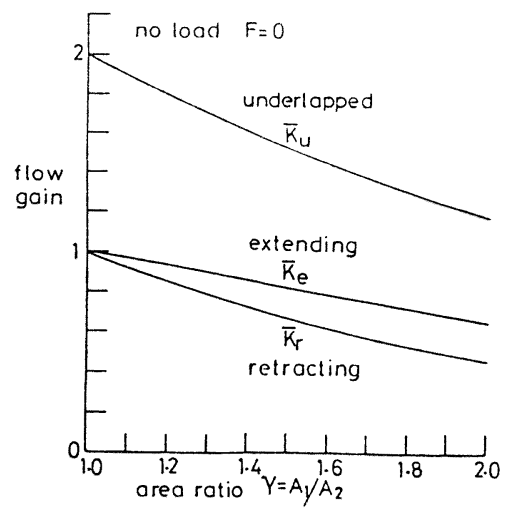

Fig. 9 Variation in system gain for a cylinder position control system with an underlapped servovalve spool

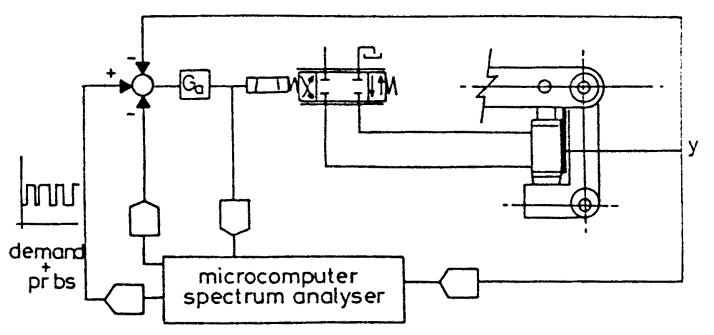

Fig. 10 System identification and adaptation using prbs testing and a simple feedback algorithm

flow rates, etc. Complex calculations such as frequency spectrum and cepstrum analysis can also be undertaken. Software packages may also be utilised for trend analysis of the component or system health. In aerospace systems "smart" redundancy is now often quoted as an example of microprocessor monitoring for making logical decisions regarding the failure or otherwise of multi-channel electrohydraulic actuators.

Fluid Power systems often form only a part of the total industrial operation and it is perhaps the area which is currently receiving the least attention from a monitoring point of view. Fluid losses alone in such areas as Mining and steel Processing can result in hundreds of thousands of pounas in replacement costs apart from costs due to failed components. It will therefore probably be consequential that Fluid Power systems will be monitored from the ciesire to initially concentrate on other components. The cost of condition monitoring has to be carefully considereci since instrumentation, cata acquisition, computer software development, personnel training, system maintenance ard calibration costs have to be carefully compared with the savings that can be realistically made. There may well be some applications where running a component to failure or replacement at regular intervals is the most cost-effective approach.

It is pertinent to now consider the parameters that can be measured in typical Fluid Power circuits. It is of course possible to take detailed measurements such as spool movements in control valves, resulting in micro-type monitoring as opposed to the more common macro-type monitoring as a result of sub-component deterioration. Such macro-type monitoring will therefore probably include:-

i) visual inspection

ii) pressure

iii) flow rate

iv) energy methods - temperature changes v) oil debris analysis

vi) vibration, particularly via acceleration changes.

An example of wear identification of a vane pump [28] is shown in Fig. 11.

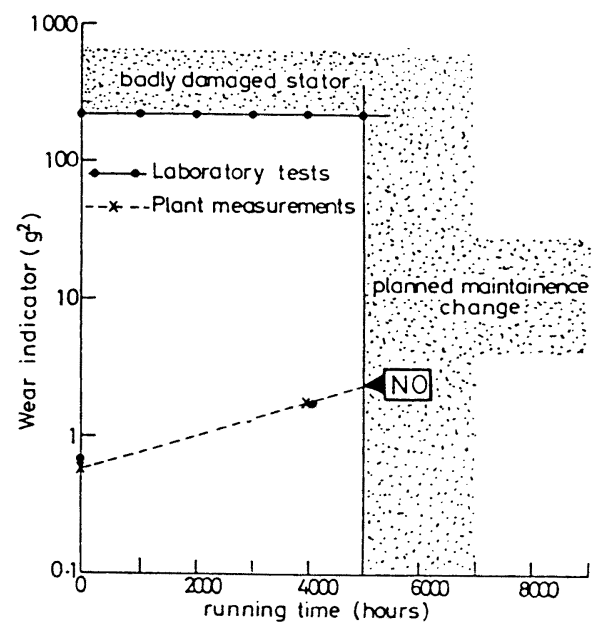

Fig. 11 Variation in acceleration mean power with running time for a vane pump [28]

Results were obtained via spectrum analysis of the accelerometer which was fixed to the pump body. This information is then integrated into a microcomputerbased condition monitoring package for system analysis.

For control systems, more thought has to be given when interpreting transducer signals. Consider for example a motor speed control system which has previously been analysed in some detail [29], and as shown in Fig. 12. 


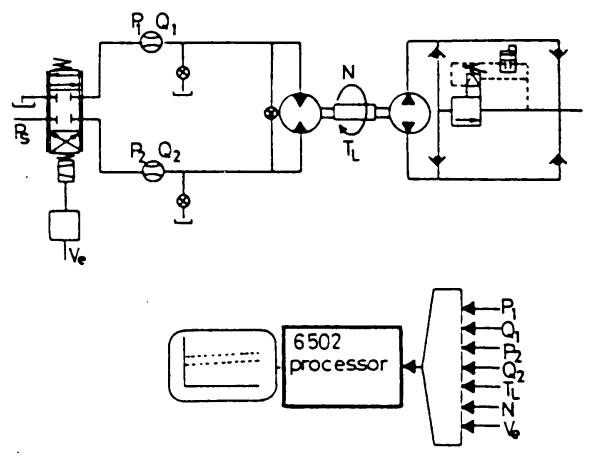

Fig. 12 Condition monitoring of a motor speed control system

A relatively low-cost personal computer-based system is used to condition monitor a servovalve/motor speed control system. Line pressures/flow rates together with motor torque/speed are monitored via 12 bit analogue to digital converters, and a set of performance characteristics are transformed into a mathematical model for the system in its run-in condition. Leakage flows are then introduced from each line, to simulate the onset of failure, and across the lines to simulate motor cross-port leakage deterioration. A graphics and software package is then developed and used to indicate which of the faults is occurring. Since this feasibility study is concerned with a servovalve/motor system, it is relatively easy to obtain data in an appropriate form to develop a mathematical model. Data is acquired at constant motor speed, and it is not too difficult to arrange for this data to be obtained automatically while the system is operating in its typical duty cycle. A Condition Monitoring strategy must combine an element of experimental experience in the way a system behaves in response to parameter changes, in this case leakage flow. By observing the interconnections and how the steady-state performance changes it is then possible to estimate the most probable cause of the change. Such experience-based approaches are now being incorporated into a technique fashionably termed Expert Systems.

A typical screen dump is shown in Fig. 13 which in this case indicates motor cross-port leakage.

Using this approach it has been possible to determine leakage flow changes of the order of $0.3 \mathrm{~L} / \mathrm{min}$ in various parts of the system.

\section{CONCLUSIONS}

The microcomputer has a powerful role to play in Fluid Power Systems design, control and monitoring. Some thought must be given regarding the complexity needed particularly where simpler solutions are clearly possible. There are applications where "total systems management" may be possible and the concept of the
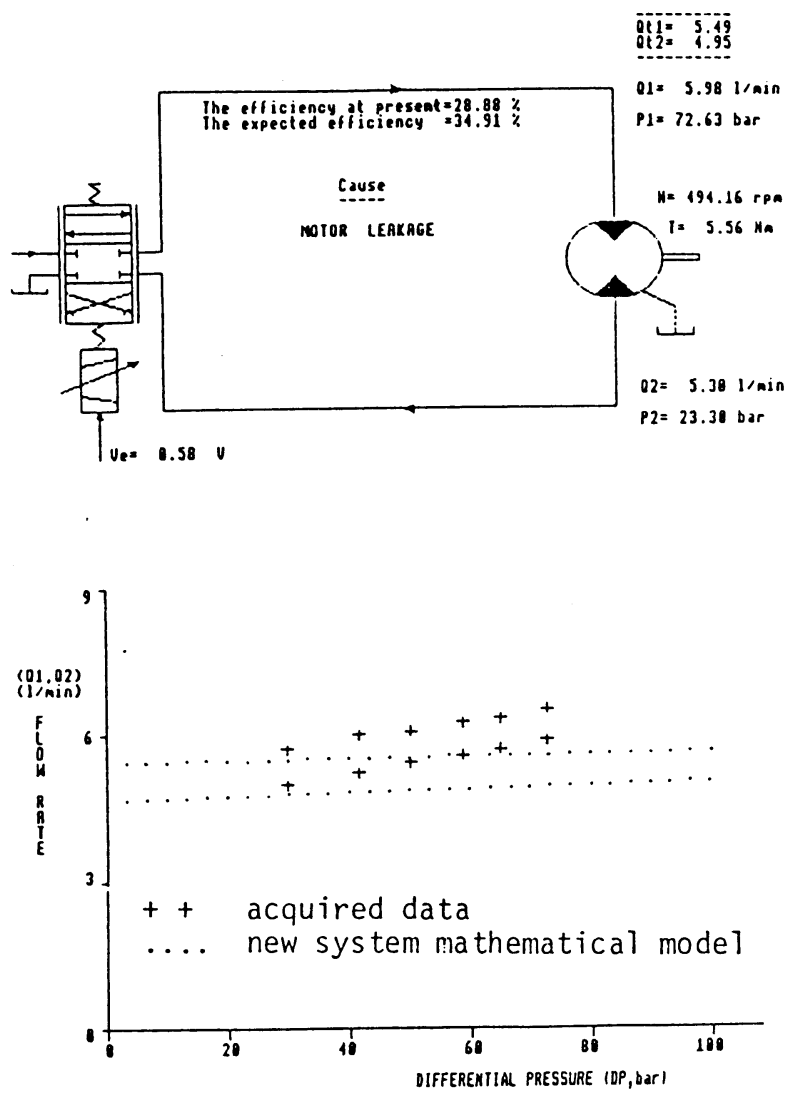

Fig. 13 A comparison of on-line data for the system with a deterioration in motor cross-port leakage

microcomputer both controlling and condition monitoring via an expert system offers an exciting challenge for the future.

\section{REFERENCES}

1. Korn, G.A. and Wait, J.U. Digital Continuous System Simulation, published by Prentice-Hall Ir.c., 1978.

2. Bajpai, A.C. and Calus, I.M. and Fairley, J.A. Numerical Methods for Engineers and Scientists, published by Taylor and Francis Ltd., 1975.

3. Shampine, L.F. and Gordon, M.K. Computer Simulation of Ordinary Differential Equations, Published by W.H. Freeman \& Co., 1975

4. Gear, C.W. "The Automatic Integration of Stiff Ordinary Differential Equations", Information Processing, North Holland Publishing Co. edited by A.J.H. Morrell, 1969, pp 187-193.

5. CYPROS - Simulation Tool for a Desktop Personal Computer, Camo, Computer-aided Modelling, N.7001, Trondheim, Norway.

6. ACSL - Advanced Continuous Simulation Language. Mitchell and Gauthier Associates Inc., Concord, M.A., or Rapid Data Ltd., Arundel, U.K. 
40

7. TUTSIM - A Dynamic Simulation System. Process Automation and Computer Systems Ltd., Lymington, U.K.

8. CTRL - C. An Interactive Computer-aided Design System. Systems Control Technology Inc., Palo Alto, California, or Rapid Data Ltd., Arundel, U.K.

9. Backe, w. and Hoffmann, w. "DSH Programme of Digital Simulation of Hydraulic Systems", 6th BHRA International Fluid Fower Symposium, Cambridge, U.K., 1981, paper Cl.

10. Bowns, D.E., Tomlinson, S.P. and Dugdale, S.K. "Progress towards a General Purpose Hydraulic System Simulation Language", Ibid, paper C2.

11. Hull, S.R., Bowns, D.E. "The Development of an Automatic Procedure for the Digital Simulation of Hydraulic Systems, Mechanical Engineering Publications Ltd. (I.Mech.E) London, November 1983, pp 67-72.

12. Backe, w., Sauerbreg, w. and Langen, A. "Component Design by DSH Programme, Ibid, pp 31-37.

13. Kinoglu, F., Riley, D., Donath, M. and Torok, D. "Streamlining Hydraulic Circuit Designs with Computer Aid", Computers in Mechanical Engineering, Vol. 1, No. 2, Oct. 1982, pp 21-26.

14. XANALOG Corporation, 215 Salem St., Woburn, MA 01801 U.S.A., arci also available from Scientific Computers Ltd., Victoria Road, Burgess Hill, West Sussex RH15 9LW, U.K.

15. Parker, G.A. and Yuksel, I. "A Novel Electrohydraulic Switching Valve", 6 th BHRA International Fluid Power Symposium, Cambridge, April 1981.

16. Mansfield, G. "Fast Switching Ball Valves on Digital Control Elements for an Electrohydraulic Servoactliator", Ibid, pp 334-348.

17. Hughes, M.L., Dewhirst, $S$ and Heron, R.A. "A Low Cost Microprocessor to Fluid Power Interface Valve", Ibid, pp 51-56.

18. Tanaka, H. and Ishihara, T. "Electrohydraulic Digital Control of Cone-roller Torroidal Traction Drive Automatic Power Transmission", ASME Journal of Dynamic Systems, Measurement and Control, Vol. 106, Dec. 1984, pp 305-310.
19. Dew-Hughes, D. "Superconductivity: Scientific Phenomenon to Engineering Reality", Proc. I.Mech.E., Vol. 202, No. C3, 1988, pp 147-159.

20. Daley, s. "study of a Fast-acting Self-tuning Control Algorithm", Proc. I.Mech.E., Vol. 200, No. C6, 1987, pp $425-430$.

21. Finney, J.M., de Pennington, A., and Gill, G.S. "A Pole Assignment Controller for an Electrohydraulic Cylinder Drive", Journal of Dynamic Systems, Measurement and Control, Vol. 107, June 1985, pp 145-150.

22. Vaughan, N.D. and Whiting, I.M. "Microprocessor Control Applied to a Non-Linear Electrohydraulic Position Control System", 7th International Fluid Power Symposium, Bâth, England, September 1986, pp 187-197.

23. Daley, S. "Application of a Fast Self-tuning Control Algorithm to a Hydraulic Test Rig", Proc. I.Mech.E., Vol. 201, No. C4, 1987, pp 285-295.

24. Edge, K.A. and Figueredo, K.R.A. "An Adaptively Controlled Electrohydraulic Servo-mechanism, Part 1: Adaptive Controller Design", Proc. I.Mech.E., Vol. 201, No. B3, 1987, pp 175-180.

25. Edge, K.A. and Figueredo, K.R.A. "An Adaptively Controlled Electrohydraulic Servo-mechanism. Part 2: Implementation", Proc. I.Nech.E., Vol. 201, No. B3, 1987, pp 181-189.

26. Watton, J. "Further Developments on the Closed-loop Response Design of Self-tuning Electrohydraulic Control Systems", 1st JHPS International Symposium on Fluid Power, Tokyo, 1989.

27. Watton, J. The Effect of Servovalve Underlap on the Accuracy and Dynamic Response of Single-Rod Actuator Position Control Systems", Journal of Fluid Control, vol. 18, 1988, pp 7-24.

28. Watkins, $\mathrm{K}$. and Watton, J. "Wear Monitoring of Positive Displacement Vane Pumps", 2nd International Conference on Condition Monitoring, London, May 1988, pp 107-115.

29. Watton, J. and Creber, D.J. "Leakage Flow Detection in a Fluid Power Speed Control system using a Personal Computer-based Condition Monitoring Package", for the Proceedings of I.Mech.E., sometime in 1989. 